\title{
Greater good, empowerment and democratization? Affordances of the crowdsourcing transcription projects
}

\author{
Joanna Iranowska*
}

\begin{abstract}
Digital technology and Internet access have created new possibilities for museums and archives for the digitization of their collections. Steadily, more museums are experimenting with inviting their audiences to participate in tagging images, annotating, transcribing historical texts or cropping photographs. This article is an exploration of visual and functional aspects of various digital interfaces frequently being used in crowdsourcing projects involving transcribing manuscripts. The empirical material has been collected through interviews with the editors of the projects and systematic technical walkthroughs of MediaWiki platforms (Edvard Munch's Writings and Transcribe Bentham) and Zooniverse platforms (AnnoTate and Shakespeare's World). The analysis aims to explore platforms' affordances (Gibson 1978), in other words the opportunities that the layout and design offer to users interacting with facsimiles of manuscripts ('digital networked objects') (Cameron and Mengler 2015). The questions raised are whether and how the interfaces empower users and provide the volunteers with agency. The platforms' interfaces have emerged as an important and undervalued actor-network of elements which configure heterogeneous relations among actors and influence users' engagement.
\end{abstract}

Key words: digitization, crowdsourcing, text collections, online participation, interfaces

\section{Introduction}

In their recently published book on participatory heritage in the culture sector, information and heritage scholars Henriette Roued-Cunliffe and Andrea Copeland observed that, when planning crowdsourcing projects in the field of cultural heritage, "collaborations tend to place more importance on content and less importance on medium' (2017: xv). Moreover, even though crowdsourcing as a model of collaboration has received much attention from cultural heritage and digital humanities scholars (see for example Ridge 2014; Roued-Cunliffe and Copeland 2017b; Bordalejo and Robinson 2016; Delwiche and Henderson Jacobs 2013), there are no comprehensive studies dealing specifically with the visual and functional aspects of crowdsourcing platforms.

As Bruno Latour has observed, technological tools often become invisible, unnoticed and taken for granted since one tends to focus on inputs and outputs and not on their internal complexity. Latour proposes to call the invisibility of technology 'blackboxing' (1999: 304). I would like to argue that the choice of a crowdsourcing platform and its layout should not be underestimated, since it is an important actor for determining the possibilities for user interaction with the digital facsimiles on the screen. Once volunteers enter a project page, the digital interface, containing the project description and menu systems, guides them around. Drawing on actor-network theory, this article aims to discuss whether and how project-interfaces perform as democratizing actors empowering the crowd. The actor-network theory is a material semiotic tool and method that 'treat everything in the social and natural worlds as a continuously generated effect of the webs of relations within which they are located' (Law 2009, 142).

The crowdsourcing projects would not have been possible without the underlying technology (Ridge 2014); thus, I find it important and interesting to explore the affordances 


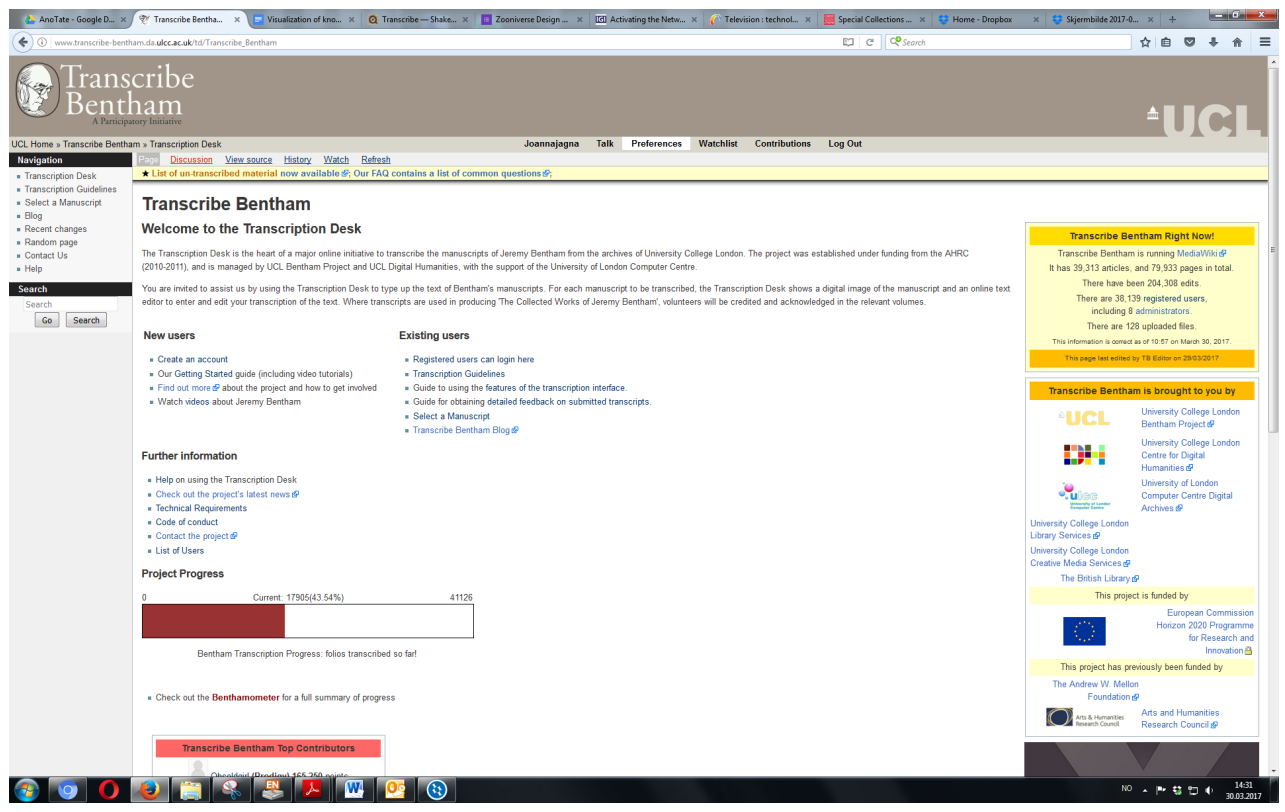

Fig 1. Home page. Transcribe Bentham. http://www.transcribe-bentham.da.ulcc.ac.uk/td/ Transcribe Bentham

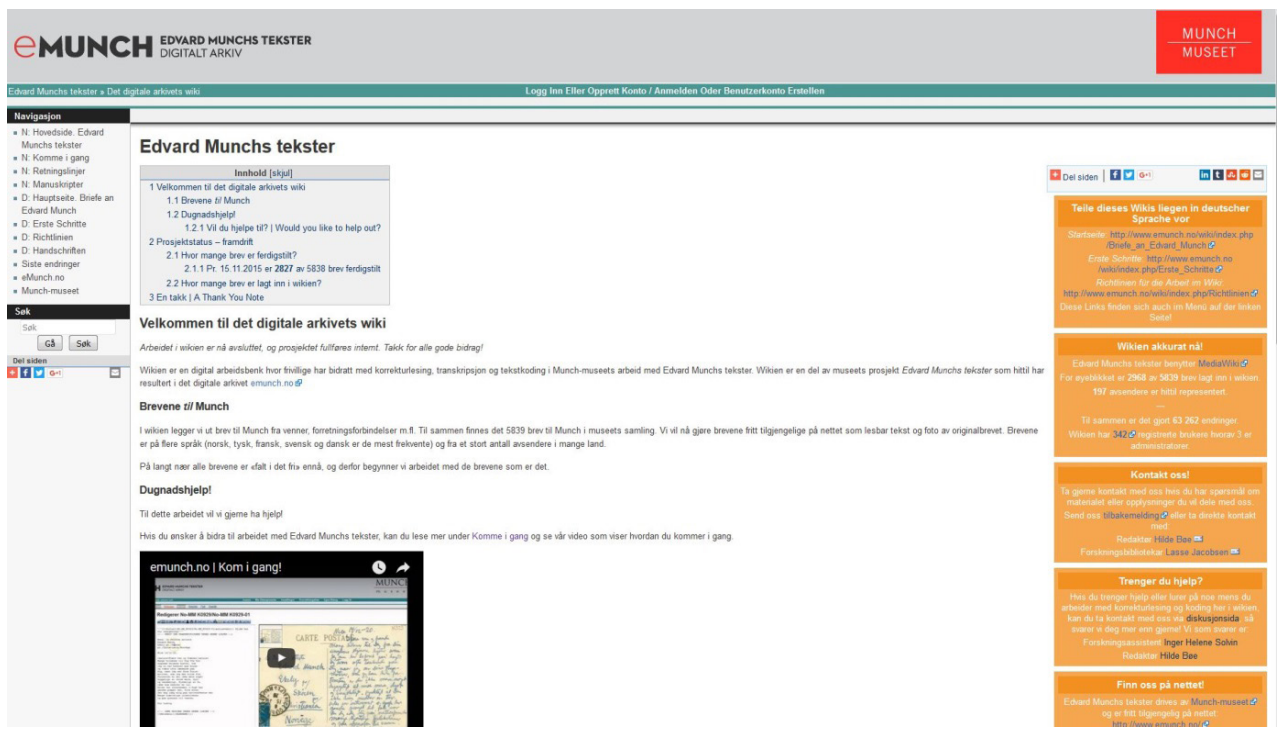

Fig. 2. Home page. Munch's Writings. www.emunch.no/wiki/ 
(Gibson 1986) of the software and user-technology interaction with the archival material mediated on the screen in the form of 'networked objects' (Cameron and Mengler 2011). I will analyze two significantly different digital environments for transcribing historical texts. The reason for this choice is that most of the crowdsourcing projects conducted by cultural institutions deal with transcribing, indexing or describing of historical records, as Blaser has argued (2014: 49). I will compare and contrast two projects established on the MediaWiki platform, Edvard Munch's Writings and Transcribe Bentham, versus two projects on the Zooniverse platform, AnnoTate and Shakespeare's World. I approach them as actor-networks of heterogeneous elements where manuscripts are immersed and enclosed within the webpage design.

The Transcribe Bentham and Edvard Munch's Writings projects were organized in a similar way in terms of their mission, their governance by cultural institutions, and their graphical interfaces. Both used the open source MediaWiki software originally designed for use on Wikipedia, which is familiar to its millions of contributors and users. The Edvard Munch's Writings project dealt with transcribing nearly 6,000 letters received by the Norwegian painter Edvard Munch (1863-1944). Led by the Munch Museum in Oslo, Norway, it ran between May 2014 and July 2016 and aimed to supplement the pre-existing digital archive (www.emunch.no) with facsimiles and encoded transcriptions. The task delegated to the users involved proofreading and encoding OCR-generated transcriptions of letters, postcards, telegrams, visit cards and other papers. The platform (see Fig.1) was modelled after the widely known and successful Transcribe Bentham project, launched in 2010 by UCL, ${ }^{1}$ whose ambition was to decipher the difficult handwriting of English jurist and philosopher Jeremy Bentham (1747/8-1832).

The two other projects under scrutiny here, Shakespeare's World and AnnoTate, are established on the Zooniverse portal (www.zooniverse.org), which is the product of a lot of grant funded research at three different institutions, the University of Oxford, the Adler Planetarium, and the University of Minnesota. The Zooniverse introduces itself as 'people powered research' and collaborates with various cultural institutions. AnnoTate (see Fig. 2), launched in 2015, aims to decipher sketchbooks, letters and personal papers of artists (e.g. Josef Herman, Barbara Hepworth and Kurt Schwitters) housed in the Tate Britain archive in London. Shakespeare's World, established in 2015, intends to transcribe of the early modern English manuscripts, and to identify words not yet in the Oxford English Dictionary. It is a three way partnership between the Zooniverse, the Folger Shakespeare Library in Washington, DC and the Oxford English Dictionary.

\section{Crowdsourcing in cultural heritage}

The model of collective problem solving governed by an organization has its origins in the business sector. The notion, a cluster of two words - crowd and outsourcing - was first proposed in 2005 by media scholar and journalist Jeff Howe. ${ }^{2}$ In the cultural sector it is also known as 'community-sourcing' (Terras 2016; Ridge 2014b; Holley 2010), 'participatory heritage' (RouedCunliffe and Copeland 2017a), and 'citizen-science' (Silvertown 2009). However, the practice of involving volunteers at cultural institutions is not a new phenomenon: 'In this sector there have always been amateur participants' (Roued-Cunliffe and Copeland 2017a: xviii; see also Tveiten Roholdt 2016). What is actually new about this form of volunteering is the technology performing as a mediator between the two parties, which is another argument for studying the technology, its possibilities and its implications.

In cultural heritage, crowdsourcing project volunteers across the globe perform tasks such as tagging images, annotating, transcribing historical texts, or cropping photographs while sitting at home in front of their computers or tablet screens. Digital humanities scholar Melissa Terras points out that '[c]rowdsourcing in the heritage sector began to gather speed around 2010 with a range of projects being launched that asked the general public for various types of help via an online interface' (2016: 9). This tendency is clearly visible in the Nordic countries, where we find more and more examples of cultural institutions launching projects where online users are invited to play new, active, responsible roles (Hylland 2014: 267). Some examples are City Archive of Copenhagen's Politiregisterbladet, National Library of Finland's Digitalkoot and Munch Museum's Edvard Munch Writings projects. 


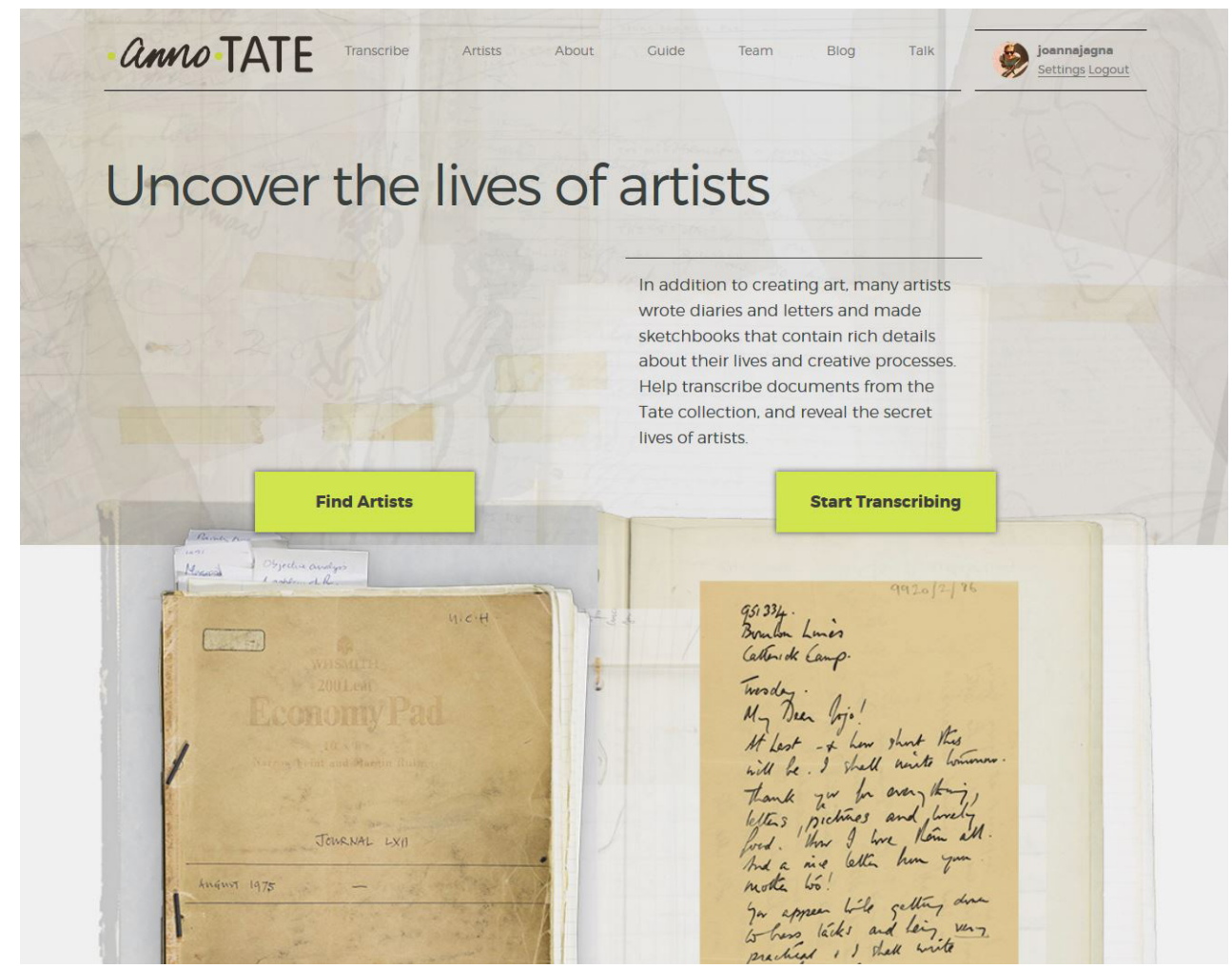

Fig. 3. Home page. AnnoTate. https://anno.tate.org.uk/

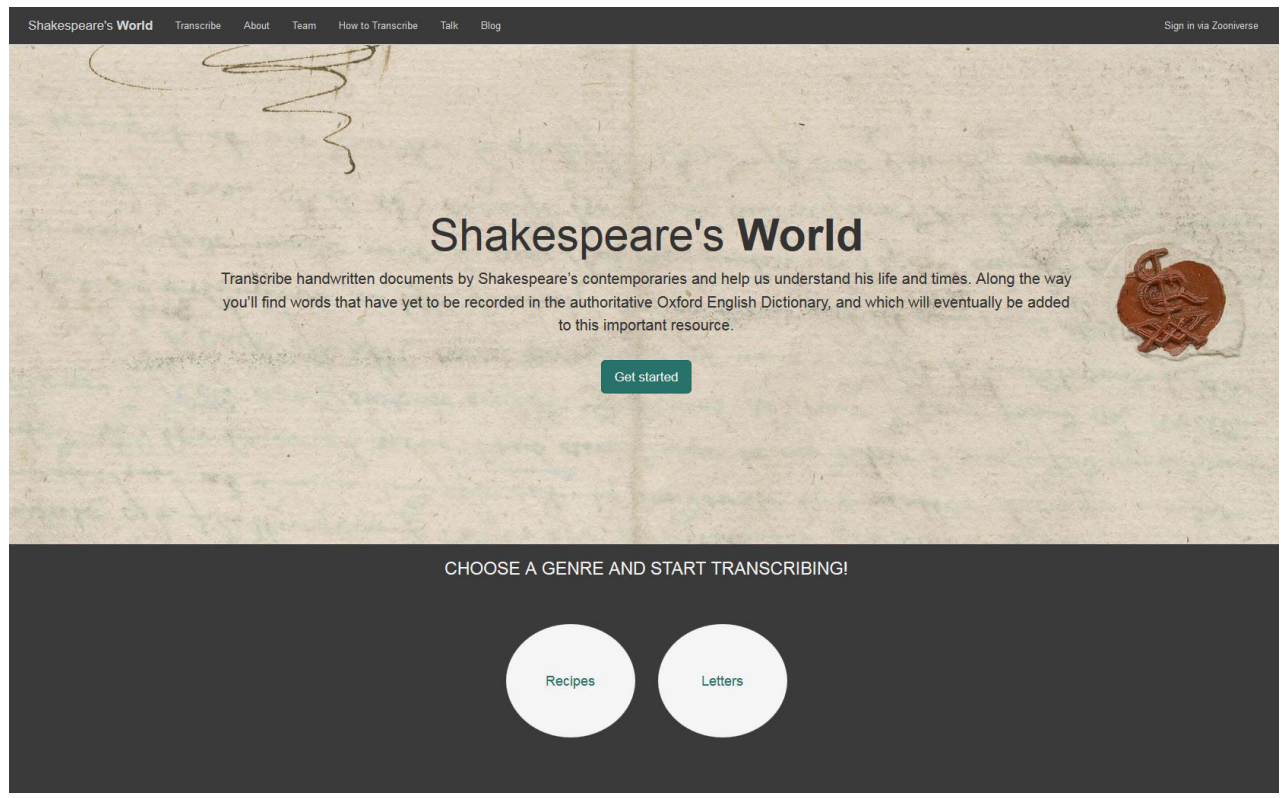

Fig 4. Home page. Shakespeare's World. https://www.shakespearesworld.org/ 


\section{Greater good, empowerment and democratization}

As Mia Ridge has observed, '[c]rowdsourcing in the cultural heritage benefits from its ability to draw upon the notion of the "greater good" in invitations to participate' (Ridge 2014b: 3). This logic is connected to the participatory turn (Simon 2010) and the phenomenon of empowerment in museums where '[p]articipation is often depicted as a democratic tool' ${ }^{3}$ (Brenna 2016: 39). In her article about measuring quality of participation in museums, Brenna describes a shift towards participation in the international and local cultural policy thinking. As a result, museums receive new tasks - despite being institutions for collecting and preserving - they become arenas for dialogue and social inclusion: "Today, it is a goal that "users" or "audiences" will engage in the production process itself, in decision-making and in the creative process, thereby contributing to the democratization of politics and cultural life' (Brenna 2016: 41). Brenna is especially interested in whether and how participation can be evaluated. Since participation is often facilitated through specific objects and technologies, a possible way is to explore the relations between these objects and audiences. Thus, after Marres (2012), Brenna encourages more studies on the materiality of things designed for fostering participation and democratization in the cultural sector. Therefore I believe that it is important to study the affordances of the crowdsourcing platforms' interfaces, since '[m]any consider digital media as the ultimate participatory tool' (Brenna 2016: 39),

The Internet and digital technology, as Bodil Axelsson has observed, brought potential solutions to museums' problems - museums have for many years struggled to become more democratic and less authoritative (2018). The idea of being democratic connects with empowering the users, which means to give them a power or authority to do something. Digital media enabled opening up the collections, reaching out towards the audiences and interacting with them. In transcription projects, museums and archives wish to gather information about their collections in the form of accurate representations of manuscripts, and in return they offer the honour of contributing to scholarship as well as the opportunity to gain new knowledge and join a community.

The Zooniverse communication strategy is based on a statement that 'anyone can be a researcher'. ${ }^{4}$ Their main page encourages readers to 'discover, teach and learn' and offers the chance for 'contributing to real discoveries' through working with actual datasets. The focus on teaching others before learning, and phrases such as 'help us understand Shakespeare's life and times'5 illustrate the will of giving authority to the users, for example through enabling them to educate each other. The Zooniverse humanities principle investigator, Victoria van Hyning, explained that the aim is to "build a system that is designed in such a way that you can trust the results and trust the crowd who transcribe or do whatever the task is. ${ }^{\prime 6}$ It would mean for example publishing online transcribed material without being proofread and checked by experts, only stating that this is crowdsourced data. Moreover, the Zooniverse encourages serendipitous discovery and adventure through the Talk platform, which I think is a nice compromise. Volunteers are asked to do structured tasks, whether that's transcribing or clicking on penguins, and then they can literally do or say anything they like on Talk, so long as it's not offensive, illegal etc. Talk is where the great discoveries have happened: new types of galaxies, new words for the Oxford English Dictionary - a partner on Shakespeare's World. ${ }^{7}$

The MediaWiki projects were advertised in a similar manner - the Transcribe Bentham homepage explained that it aims 'to engage the public in the online transcription (or typing) of original and unstudied manuscript papers written by Jeremy Bentham.' It invites people to 'contribute to research,' 'preserve important documents', 'learn about Bentham, philosophy and palaeography,' and 'have fun.' The users are 'invited to assist [the research team] by using the Transcription Desk to type up;' this is more cautious choice of words than in the case of the Zooniverse platform, which seems to want to empower their users more than by simply letting them to assist. All in all, all the analyzed projects stressed the various competencies of the crowd and offered them an active role in preserving historical texts through transcribing.

Along with emphasizing of the democratizing aspects of crowdsourcing by its enthusiasts, a number of political and ethical issues have been raised. Organizations playing an active 
role in the digitization projects and partnering with the cultural institutions are often private companies, for example Google, or non-governmental bodies, as in MediaWiki and Zooniverse. In addition to democratization of access to collections, we are also witnessing a redistribution of power in the cultural sector - private stakeholders started serving the missions traditionally reserved for the public sector - 'digitized cultural heritage has also become a focal point for global companies' (Hylland 2017: 68). In addition, some criticize the practice of delegating tasks to volunteers rather than paying the experts and lodge charges of 'click servitude,' 'digital slavery,' and 'crowdsploitation' (Brabham 2013: 85-86).

\section{Networked objects and affordances}

The act of digitizing a manuscript results in the flattening of a three-dimensional object and translating it into a new digital entity to be viewed on a computer screen. When digitized and uploaded online, a manuscript is turned into what museum theorists Fiona Cameron and Sarah Mengler propose to call a networked object, which 'acts as a mediator between the museum world and public culture as it circulates between these spaces, and in various cultural, social, political and technological formations, consumed in many different and unexpected ways' (2011: 166). The digital facsimiles of the manuscripts enter global flows and circulate between museums' webpages, museums' hard drives, users' screens and social media. In the crowdsourcing transcription projects, a single web page is a networked object, consisting of an image of a manuscript, crucial metadata, web page menu systems, a transcription box with a toolbar and different icons, buttons, frames, hyperlinks and hypertext surrounding it. Bruno Latour's notion of mediators, on which Cameron and Mengler drew, serves as a useful analytical tool to understand the role of these elements when users interact with manuscripts. The networked objects behave as mediators; they enable the transcription and production of new knowledge about the manuscripts through the interactions they invoke - in that way they 'transform, translate, distort, and modify the meaning or the elements they are supposed to carry' (Latour 2007: 39). Mediators' characteristics may include user interface arrangement, functions and features, textual context and tone, and symbolic representations (Light et al. 2016: 11-12).

To borrow a term from James J. Gibson $(1978,1986)$, possibilities of interacting offered to the users can be called affordances. The basic idea of affordances can be stated as the perceivable possibility of an action on an object or environment. The composition and layout of the crowdsourcing platforms constitute their affordances. Gibson claims that, when an animal perceives its environment visually, it focuses mostly on the opportunities it offers and not on its aesthetic qualities (Gibson 1986: 134). Crowdsourcing platforms are assemblages of images, text, menu systems, buttons, icons, hyperlinks, animations, and other webpages' elements, which afford, among other things, browsing the images of archival material and transcribing text from images. Notably, Gibson distinguishes between positive (beneficial) and negative (injurious) affordances (1986: 137), which would mean that interface elements can have either an encouraging or a discouraging effect on the users.

An important question arises, namely - what is the difference between affordance and 'agency' of things? The term 'agency' is used in material semiotics and actor-network theory (ANT) in order to emphasize that non-human entities have power to act, and that they are not diametrically ontologically different from humans (Latour 2013a: 291). In the light of ANT both human and non-human entities are actors possessing agency, which means that they contribute to transforming reality. I read the project's interfaces as actors (Gosden, Larson, and Petch 2007; see also Latour 2007) which are capable of assembling an actor-network of professionals, volunteer workers, hardware and software around them. Notably, the ANT focuses solely on exploring actions actually undertaken and relations between actors at work in the network. Comparatively, an affordance seems to be a broader notion since it emphasizes all the potential actions to be conducted on an object - not only those actually undertaken. In the following, I attempt to combine these two perspectives in order to gain deeper insight into the user-networked object interactions. 


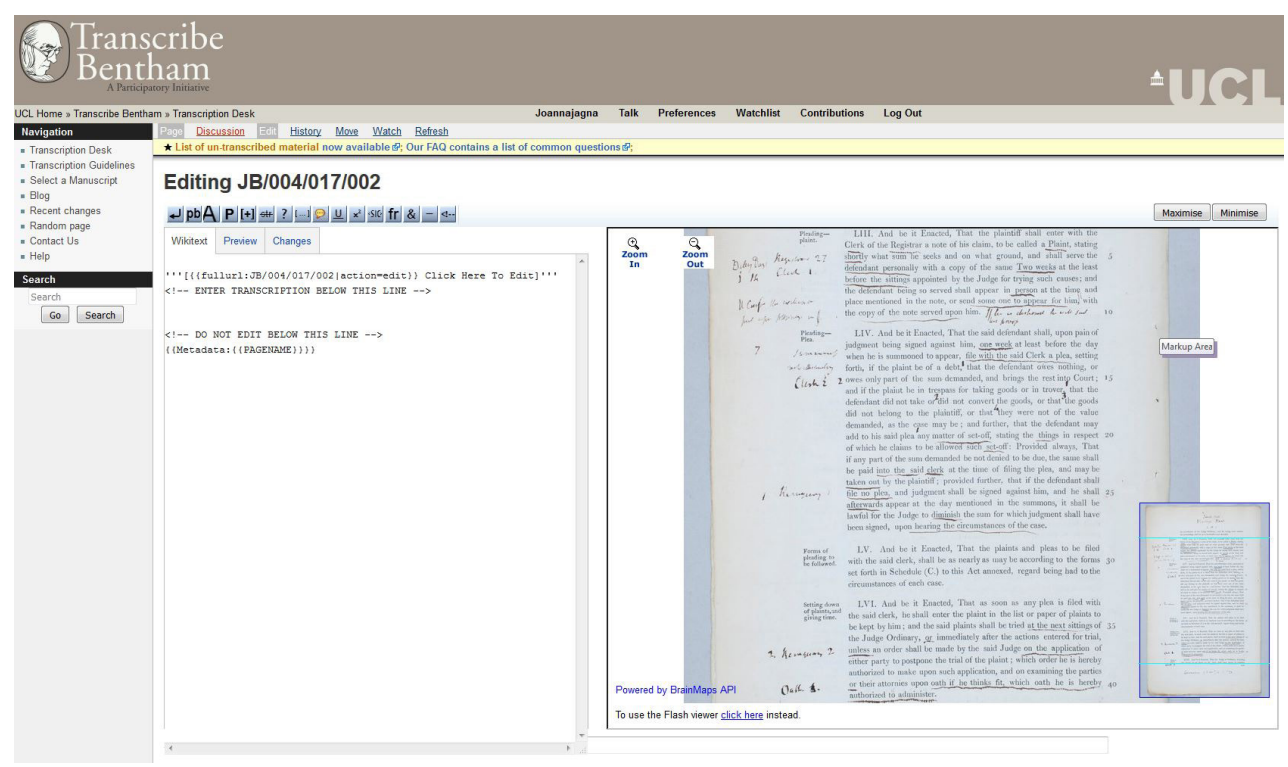

Fig. 5. Transcription desk. Transcribe Bentham.

\section{Method}

To explore platform affordances and their role in empowering the users, I have applied different qualitative investigation techniques: technical walkthroughs which resulted in hundreds of screenshots, interviews with the projects' editors, observation of the volunteers and an online questionnaire. In addition, between 2012 and 2015, I was an Edvard Munch's Writings research assistant, which allowed me an insider's perspective.

The walkthrough method, initially described by Clayton Lewis, Peter Polson, Cathleen Wharton and John Rieman (1990), is a tool for software inspection and evaluating user interface (Nielsen 1994) - it means testing the interface with a real user. This method allowed me to observe a user trying transcription tasks in two different digital environments: MediaWiki (Transcribe Bentham) and Zooniverse (Shakespeare's World). The screen picture and their voice during the walkthrough was recorded (elements of talk-aloud protocol has been used). Afterwards, I interviewed the user, focusing my questions on their experience of various digital environments.

In addition, in order to gain detailed insights into all the scrutinized projects, I spent a month (April 2017) conducting systematic walkthroughs on my own, placing myself in the user position as proposed by Ben Light, Jean Burgess and Stefanie Duguay (2016). I actively engaged with the interface features while transcribing on a daily basis. Using screenshots and detailed field notes and recordings, I focused on observing how the networked objects were embedded in platforms and on tracing key actors of the digital interface (mediators) manuscripts' facsimiles, buttons, frames, hyperlinks and inscriptions.

Moreover, I conducted extensive interviews with editors and researchers behind all the scrutinized projects, asking about their decisions concerning the choice of interface and its consequences for the users' engagement, empowerment and participation rate. I spoke to coordinator of Transcribe Bentham (Louise Seaward), to the digital collection manager in the Munch Museum (Hilde Bøe), to a Digital Humanities postdoctoral fellow at Zooniverse (Samantha Blickhan), and to the Zooniverse's humanities principal investigator (Victoria van Hyning).

An online questionnaire directed towards the volunteers of Edvard Munch's Writings provided insight into their motivation, the perceived complexity of the tasks and their experiences of the platforms' design and affordances. The number of responses turned out to be too small 
to be analyzed from a quantitative point of view; nevertheless, the answers served as rich qualitative material. The combination of all the mentioned tools enabled me to explore the user-technology interaction from different perspectives.

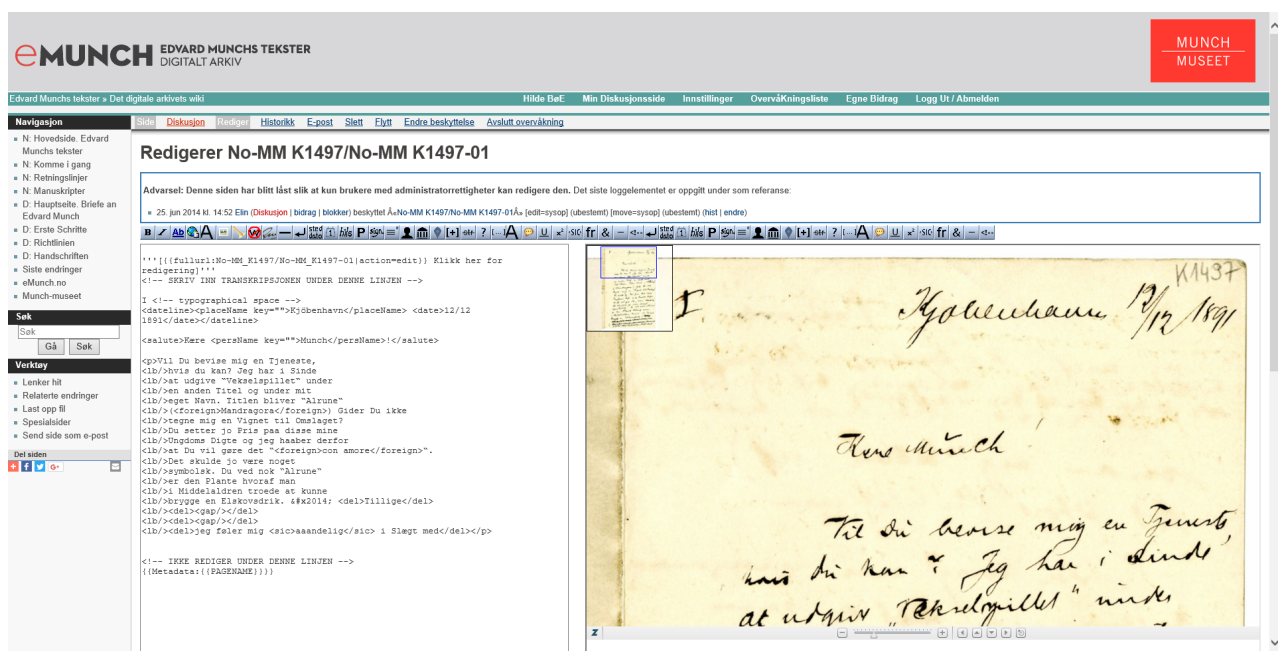

Fig. 6. Transcription desk. Edvard Munch's Writings.

\section{Affordances of homepages}

All the projects I looked at dealt with the transcription of similar types of archival material. However, the affordances of the compositions and layout and, moreover, how the projects' visions were framed differed considerably on their website homepages. The affordances I consider in this analysis were the possibilities that the digital environment offered for a user sitting in front of a computer screen.

The MediaWiki homepages (see Fig. 1 and Fig. 2) consisted of three different menu systems (on the left, on the right and at the top) and multiple text sections with headings. Edvard Munch's Writings introduced itself as 'a digital workbench where volunteers could contribute with proofreading, transcribing and encoding', but an actual invitation to contribute to the project was not articulated until the very last text section, which said: 'If you wish to contribute, you might read more in the section "get started" and watch our videos.' This gentle encouragement was not emphasized in the actor-network of the different webpage elements and therefore did not turn out to be very persuasive in either a rhetorical or a visual sense. Similarly, the Transcribe Bentham's project chose to explain its purpose with a lengthy text on their homepage - the project aimed to 'transcribe the material, to help the work of UCL's Bentham Project, and further improve access to, and the searchability of, this enormously important collection of historical and philosophical material.' Both MediaWiki homepages were readable and browse-able - they were rich in text and offered much information about the projects. However, their interfaces did not focus on sparking interest and curiosity through their visual form. For an average person taking only a couple of seconds to orient herself to the content, it might have been discouraging, since the number of buttons and amount of text made it unclear how to start transcribing. Instead of including a clear indicator marked 'Start transcribing', as the Zooniverse homepages did, the MediaWiki homepages consisted of multiple links, for example 'Transcription desk', 'Create account' (repeated twice) and 'Getting started guide', however, none of these took the user directly to the transcription page. The constraints in the design might be explained with the fact that the MediaWiki platform was not created specifically for transcribing historical texts, but has emerged from the existing Wikipedia community, and has been adapted to digital heritage projects. 
Moreover, in the case of Edvard Munch's Writings, the language of the website might have behaved as a negative affordance, since it was available only in Norwegian and German. Consequently, the project's target group was much smaller than in the case of projects directed towards English-speaking users.

The digital environments of the Zooniverse homepages (see Fig. 3 and Fig. 4) combined a piece of archival material as a background with just a few lines of text briefly articulating the purpose of the initiatives. A catchphrase on the AnnoTate homepage called users to '[u]ncover the lives of artists' and '[help] to reveal the inspiration and stories behind some of the greatest works of the past century', while Shakespeare's World invited one to ' $[t]$ ranscribe handwritten documents by Shakespeare's contemporaries and help us understand his life and times'. The affordances of the two manuscripts embedded in the AnnoTate homepage were very limited - they are viewable and readable, non-zoomable and, last but not least, non-touchable and non-tangible. All these were consequences of the physical properties of the facsimiles - their flatness and digital form. Framed within the homepage, they performed as graphical illustrations and decorations and did not afford transcribing. The homepage offered a single-click on one of the buttons ('Find Artist', 'Start Transcribing', top menu or bottom menu), reading the content, and scrolling the page up and down. However, the top and bottom menus were very discreet (small font, grey dull colour, inconspicuous placement), while two featured, centrally located rectangular green buttons were designed to attract attention. The page afforded a choice between picking an author and starting from a random page. Comparatively, in Shakespeare's World one could not choose a manuscript or author, but rather was taken to a random page every time, which could be perceived as negative or positive affordance, depending on the users' preferences about how much guidance they like. Importantly, the Zooniverse transcription projects permitted transcribing without obligatory registration, differently from the MediaWiki platforms. As one of the interviewed users said, '[it] tries to make it easy to get in, and lower the threshold of starting to engage'.

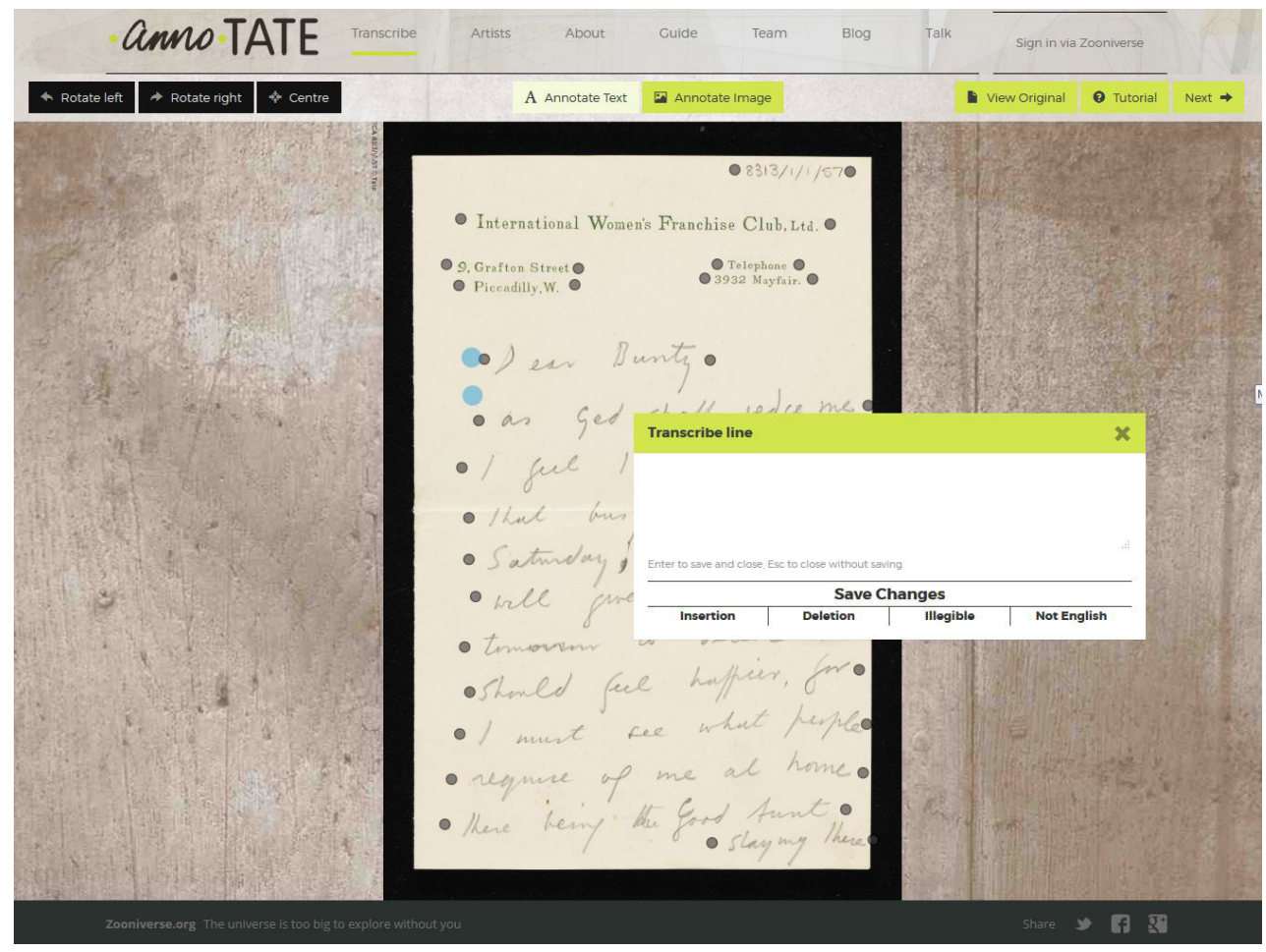

Fig. 7. Transcription desk. AnnoTate. 


\section{Affordances of the transcription desks}

The transcription desk is at the heart of every transcription crowdsourcing project. It affords volunteers to read or proofread, transcribe and insert mark-up tags (which will be discussed in detail later). The complexity of the task is dependent on the project. The transcription desk typically consists of a zoomable image of a manuscript juxtaposed with a data entry box with a toolbar. Different interfaces determine different strategies for completing transcription tasks. Transcriptions made by users are not always accurate, since they might transcribe with mistakes, omit passages, leave empty pages and add their own comments. In general, the transcription box interfaces were designed to be simple and intuitive; however, they are not always experienced as such at once, as described in my notes from a user observation session:

It's a lengthy, complex manuscript written by Nicholas Webster (fl. 1650) entitled 'Certain profitable and well experienced collections for making conserve of fruits... as also of surgery, approved medicines'. The participant is clicking around, rather confused. She opens an instruction and closes it quickly after having it up on the screen for 5 seconds. She clicks on 'Transcribe text'. Then ' $A$ ', which triggers 'Alphabet', a side panel with an explanation of minuscules. Next, she chooses a button 'I'm done', even though she's not. She keeps on trying around for a while. After one minute and 15 seconds she manages to open the transcription box. She drags it around, not sure which sentence from the manuscript to transcribe. Suddenly, she closes the transcription box, and, by chance, she's opening it again. Then she's zooming the manuscript in and out for a while. She gives up, and goes to the next page. It's less text, only a couple of lines, but she doesn't remember how to open the transcription box. 'How on earth is this supposed to work?' she asks, rhetorically and slightly irritated.

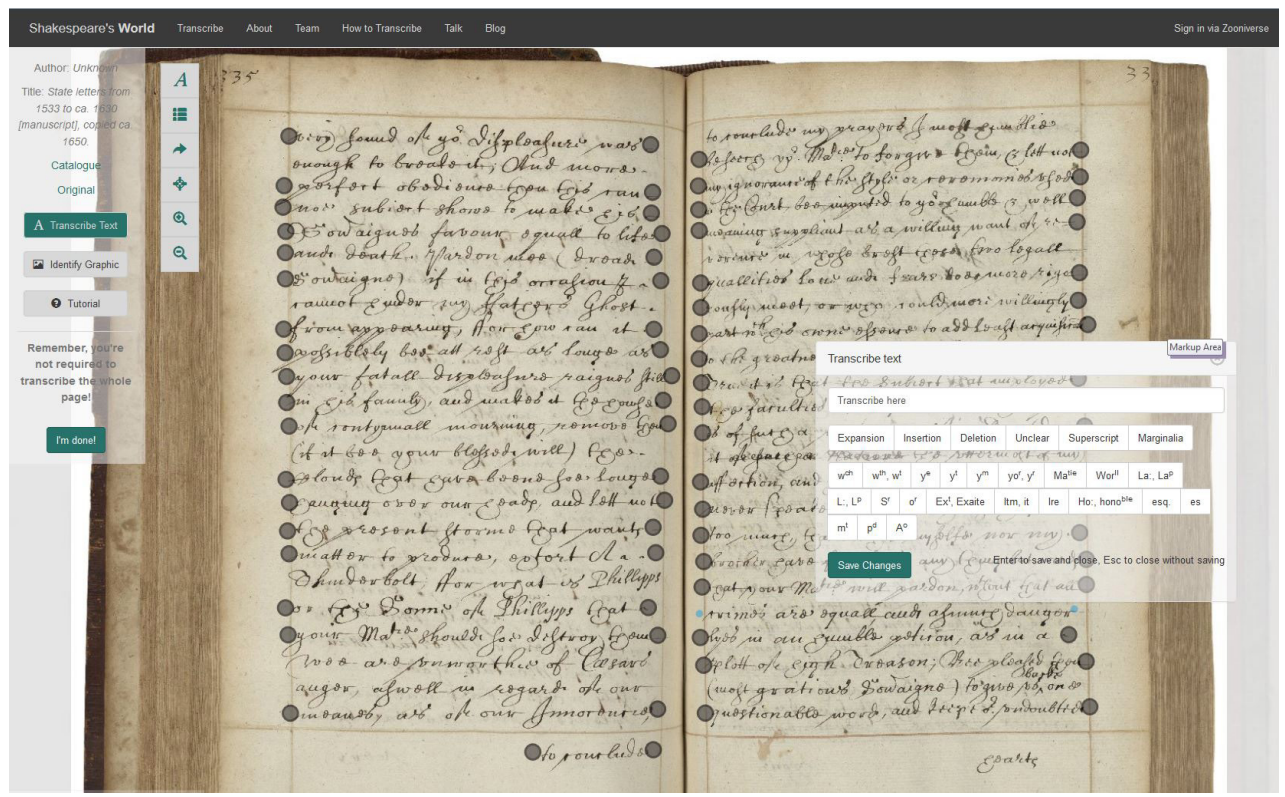

Fig. 8. Transcription desk. Shakespeare's World.

Despite knowing the context and being familiar with different transcription projects from before, the observed participant was confused, and even after looking up the guidelines, was not able to understand the basic functionalities of the transcription desk. It took her around five minutes 


\section{EMUNCH EDMRD MUNCHS TEKSTRR}

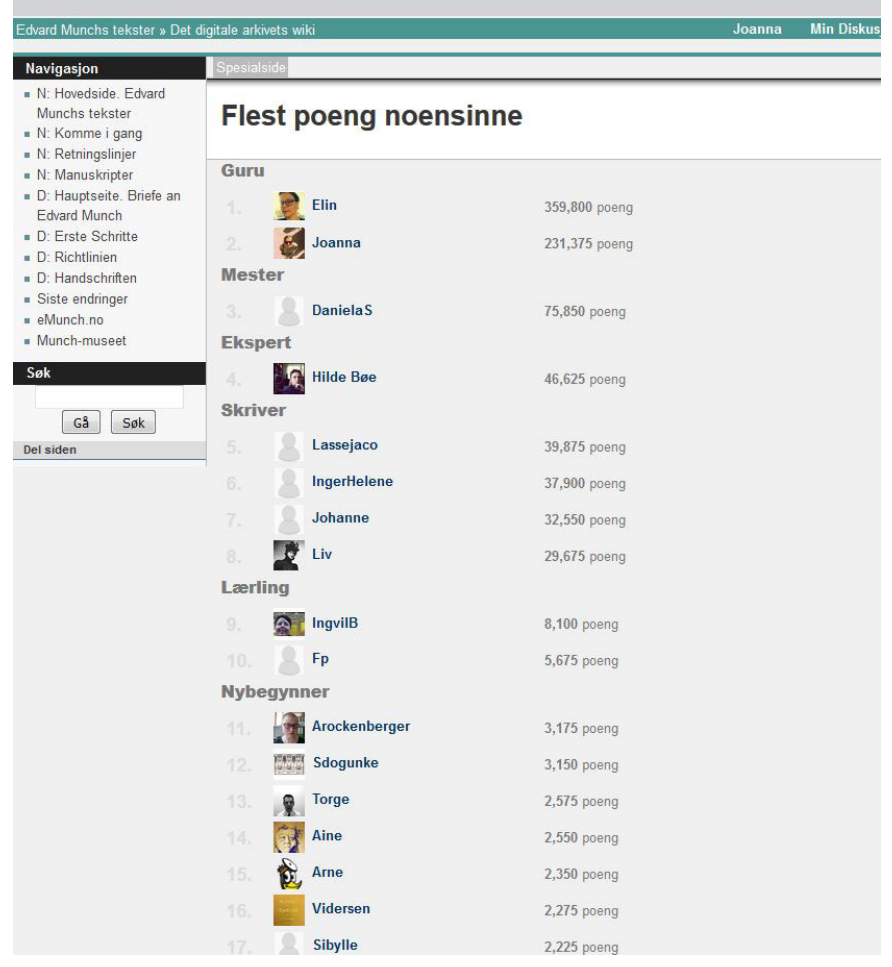

Fig. 9. Transcription desk. Transcribe Bentham. of clicking around to find out how to start to transcribe (almost four minutes longer than when being observed using MediaWiki); but once she had learned, it went much more quickly. She transcribed only what she felt confident about, picking short phrases from each page. She started from 'A very friend of' [sic!], which she marked by clicking before the first and after the last word which triggered blue dots appearing before and after the phrase. A drag-able transcription box opened, with space for one line of text only.

The most striking difference between the comparedenvironmentswas how much text volunteers were expected to transcribe. In the Zooniverse projects, a constant reminder in the lower left corner said: 'Remember, you're not required to transcribe the whole page!' The idea of transcribing as little as a line or only one word was developed with the average

time-pressed user in mind. ${ }^{9}$ The approach of segmenting and breaking the task down aims to support the learning process: 'When you start learning to transcribe...usually you don't start with the first word on the page. You may not be able to read it, ${ }^{10}$ explained the Zooniverse's humanities principal investigator. In contrast, most of the MediaWiki projects' volunteers transcribed all pages (see Fig. 5 and Fig. 6). The Transcribe Bentham coordinator clarified that tiny contributions are welcome too, but it is not the main approach. What is more, in the MediaWiki projects each page afforded being transcribed only once and was typically locked by an editor afterwards, while in Zooniverse the transcription box allowed multiple users to transcribe the same phrases many times for initial quality control.

In both type of platforms, the volunteers were expected not only to decode the content but also to encode the structural features of the text such as underlines or erasures by using the integrated toolbar. The toolbar buttons guided users to interact, configured relations among the actors (editors, volunteers and facsimiles). By doing so, they behaved as Latourian mediators. The functions of the buttons were projected upon tiny graphical icons; for example, '?' represents tagging an illegible text, and three dots in a speech balloon trigger inserting a comment.

In Transcribe Bentham, the toolbar contained of 16 different buttons: 'Line break', 'Page break', 'Heading', 'Paragraph', 'Addition', 'Deletion', 'Questionable', 'Illegible', 'Marginal Note', 'Underline', 'Superscript', 'Unusual Spelling', 'Foreign', 'Ampersand', 'Long dash' and 'Comment'. Their use generated a TEI XML code, ${ }^{11}$ for example <hi rend="underline" $></$ hi $>$, into which a marked phrase was wrapped. The buttons were supposed to simplify the encoding process since the XML code did not have to be memorized. 


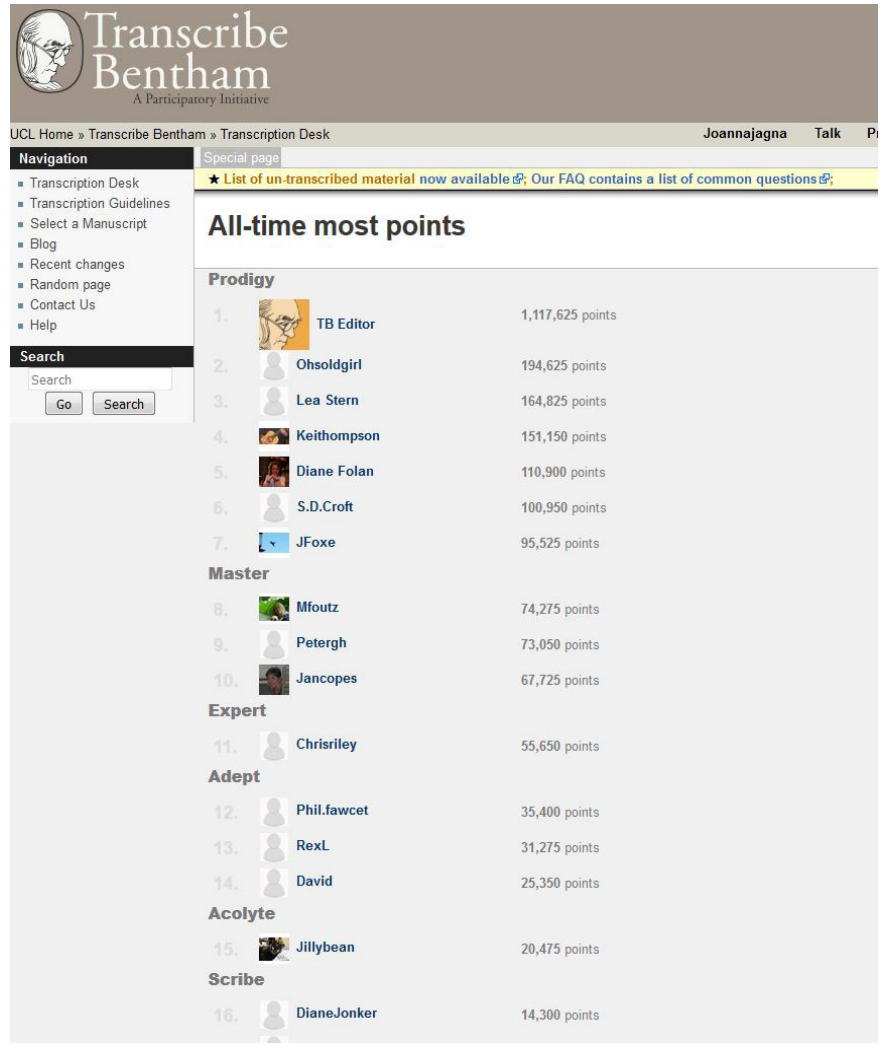

Fig. 10. Leader board. Edvard Munch's Writings.
The toolbar on the Zooniverse transcription desk consisted of fewer buttonsthanin the MediaWiki environment. The AnnoTate toolbar (see Fig. 7) afforded encoding of four basic text features: an 'Insertion', a 'Deletion', an 'Illegible' text and foreign words ('Not English'). Shakespeare's World (see Fig. 8) had those and three additional ones an 'Expansion', 'Superscript' and 'Marginalia'. When coming across a phrase containing any of these, one was supposed to mark and encode it by clicking a button. As a result, only the final output was visible; differently from the MediaWiki projects where XML mark-up tags ${ }^{12}$ were visible for the users while transcribing. Asking the volunteer transcribers to understand and use basics of TEI is a huge difference from many public crowdsourcing projects such as Zooniverse where people are unlikely to have

heard of XML mark-up. This major difference between MediaWiki platforms and Zooniverse makes it interesting to contrast and compare them.

When asked to rank how difficult it was to insert TEl encoding in the Edvard Munch's Writings project, users answered 'medium' or 'very easy', but it should be taken into consideration that most of them were familiar with TEI standard from before. However, some experienced users found the toolbar buttons unnecessary - one of the volunteers admitted, 'Sure, I can press the buttons, but it's faster if I write the code myself.'

The observation of a person transcribing Bentham's bill for establishing courts of local jurisdiction (JB/004/017/002; see Fig. 5), a printed folio containing handwritten corrections and minor notes, confirmed that statement. During transcribing, when she wished to encode an illegible text, she started to manually type tags that she knew from before instead of clicking the buttons. She typed an empty element '</unclear ', instead of generating its longer version which the toolbar would have generated, '<unclear $><$ /unclear $>$ '.

A: Do I have to use the tags they have or can I... Because I would have done it differently.

$\mathrm{J}$ : What would you have done differently?

A: Because I would make an empty element instead of doing this ' $<$ unclear $><$ I unclear>'. 
A similar situation occurred when she marked a part of a text and manually encoded it as a '<section>', and the affordances of the platform enabled her to do so, even though the only segmentation tag available in the toolbar was a '<paragraph>'.

However, the manually inserted <section>-tag was most likely removed later during the editors' quality control, since according to the project guidelines, only the tags from the toolbar should be used to encode the structural features of the text. The usage of the <section> instead of <paragraph> would disturb the coherence of the encoding of the corpus of letters.

For the reasons described, occasionally platforms' affordances create controversies (to use another Latourian term) and turn out to be problematic. Although the tasks were supposed to be solved in a specific way, described in the guidelines, some users started to use the platforms in an unexpected way. ${ }^{13}$ Besides coming up with unusual tags, it is easy to imagine scenarios of filling the transcription boxes with vulgarities, song lyrics and all sorts of nonsense, since they afford the writing of any possible text. Victoria van Hyning, the Zooniverse's humanities principal investigator, explained that although the transcription interfaces in AnnoTate and Shakespeare's World have clickable keyboards so volunteers can embed tags, it is often the case that if you do not provide these things, volunteers will either ask for them, make up their own, and indeed enforce or police a space and try to get other volunteers to follow 'the rules'.

Moreover, the Edvard Munch's Writings project's coordinator admitted that including too many toolbar buttons might have discouraged some people ${ }^{14}$ and therefore could have worked as a negative affordance of the interface. That concern corresponded with the point made by Andrew Barry, that too many strict rules impede creativity and the will to participate (2001: 149). The transcribing guidelines available in video and text form could be understood as the authoritarian voice of the institutions behind the projects. Resultantly, the empowerment of the users through the interface was quite limited, as the task delegated through the interface was expected to be solved in one specific way. Therefore, the ideas of participation and democratic knowledge production functioned within strictly defined framework and standards.

Last but not least, the affordances of the transcription desk depend on the size of the screen, the hardware (PC; laptop or tablet) and the web browser. A volunteer I spoke to expressed concerns about that: 'I mean, I have a big screen and it's relatively good, but most of the people from home, they don't have desktop anymore. ${ }^{15}$ All these are external factors beyond the control of the cultural institutions behind the projects.

\section{Affordances of gamification}

Despite their virtual form, webpages depend on interactions with humans. The involvement of human actors is crucial for the crowdsourcing projects to work; therefore, affordances 'must also be capable of gathering people together and of inducing them to follow well-drafted instructions' (Laet and Mol 2000: 234-35). A popular way of sustaining interest is introducing gamification, which is expected to work as a motivation amplifier, create long-lasting interest and offer users the feeling of being competent ${ }^{16}$ (Huotari and Hamari 2012: 19). The idea of gamification is about giving people an engaging experience through adding game-design elements and principles in non-game contexts. Projects such as Google Image Labeler, Artigo ('the crowdsourcing game of art history') and InGress the Game (Google's indirect tool for data collection) are all examples of successful implementation of game elements.

Both of the MediaWiki platforms I have analyzed introduced point systems and leaderboards. Since registration in these projects was obligatory, all the users participated in collecting points and climbed the chart. For some participants transcribing became a form of competition. Users were awarded points mainly for transcribing, but also for adding a new friend or a comment. The number of points was supposed to reflect ten different levels of users' proficiency in transcribing - Probationer, Novice, Apprentice, Scribe, Amanuensis, Acolyte, Adept, Expert, Master and Prodigy (see. Fig. 9). Analogous levels (translated into Norwegian) functioned in the Edvard Edvard Munch's Writings platform (see. Fig. 10). However, interestingly, in both cases, gamification did not improve the interest as expected. The coordinator of Transcribe Bentham admitted that, according to their findings, gamification was not that important to their users: 'They enjoy the task, and it's the value of the task that motivates them. Not being a winner.'17 What is more, the leaderboards showed that volunteers' involvement differed greatly. Only a small group of users submitted work on a regular basis and kept the project going (Causer and 
Wallace 2012; Causer and Terras 2014). This type of participation structure is rather typical for online projects and has been described as 'the 1\% 'rule' (Hargittai and Walejko 2008), known also as a 'rule of thumb'. In Internet culture, only a core group actively creates new content, whereas the rest of the users only lurk. Hence, the MediaWiki projects' editors acknowledge that the initiatives did not appeal to a real 'crowd' and, therefore, it is more accurate to speak of 'niche-crowdsourcing'18 or 'crowd-sifting' (Causer and Terras 2014: 73).

Foteini Valeonti, founder of an online crowdsourced art museum (Useum), made an important point that gamification understood only as the adding of a point system and a leaderboard is not enough: 'Gamification is about fundamental understanding of what is pleasurable for people. ${ }^{19}$ She argued that affording users the feeling of being competent creates engagement. Another crowdsourcing theorist, Mia Ridge, spoke in a similar tone, positing that concentrating on the number of pages transcribed may result in people rushing through the pages and focusing on quantity rather than quality of their contributions. How projects

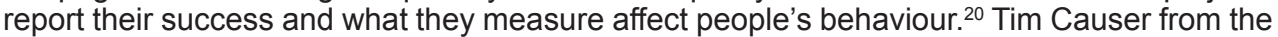
Bentham Project seemed to share their view when he warned, 'be sure the volunteers don't feel like they replace machines. ${ }^{21}$ It is not a farfetched concern, since Transcribe Bentham experiments with incorporating computational Handwritten Text Recognition (HTR) using tranSciptorium software.

When it comes to the Zooniverse projects, researchers behind them consciously avoided introducing any gamification elements. They focused on the importance of the interface, affording their users to interact with real research questions and real datasets without being put under the filter of a game. ${ }^{22}$ Their concern was that gamification might have taken away some part of the seriousness of interacting with real-life research projects. ${ }^{23} \mathrm{All}$ in all, it seems as if game elements may behave both as positive and negative affordances - they might attract or repel users in some situations when used improperly.

\section{Timespan and durability of affordances}

The existence of platforms and so their affordances are limited in time - some projects last longer than others; therefore it is interesting to consider their material and strategic durability after their foundations, and its consequences. Following John Law, crowdsourcing platforms can be considered non-bodily physical forms which, 'tend to hold their shape better than those that simply depend on face-to-face interaction' (2009: 148). However, despite the material they are made of, their durability depends also on other variables in the web of associations - such as funding, which is usually indicated as the reason for a platform's transitory nature.

Limited existence in time reduces the possibilities of user-platform interactions and the achievement of their full potential. As Causer and Terras reported, 'The first six months were undoubtedly the hardest for the Transcribe Bentham (as they would be for any crowdsourcing project attempting to establish itself)' (2014: 84). Building a platform and a community around a project from scratch is a big challenge. Nevertheless, despite having initial funding for only six months, today, almost ten years later, Transcribe Bentham is still running. Although Edvard Munch's Writings was modeled after it, its time span was almost ten times shorter. Its coordinator admitted that a longer time span could possibly improve the number of manuscripts transcribed. The short duration was caused by project-based funding. ${ }^{24}$ The Bentham Project is funded until the end of 2018 and will need to apply for new funding - the project team has calculated that '[i]f the transcribers keep going at the current rate they could finish transcribing everything by $2035 .{ }^{\prime 25}$

In the Zooniverse's work model the Zooniverse itself is not the driver of the project. Their teams build the technology and advises on its use, and the cultural heritage and academic institutions drive the project after launch. Both AnnoTate and Shakespeare's World were dependent on project funding, and supported for three years at the time of their launching in 2015. When building a new project, a team works on it on a full-time basis. However, after it is launched, it is very much reduced due to limited human resources: 'Some teams might be able to have some default time for six months after the project launches, when there tends to be the most activity', explained Victoria van Hyning, the Zooniverse's humanities principal investigator. ${ }^{26}$ 
In connection to all that, a question about the legacy of the crowdsourcing projects arises, namely, what happens afterwards? Most of the crowdsourcing platforms are not a long term storage place, but data generation place. However, many platforms do not disappear at once, and the sites might be archived. The Edvard Munch's Writing remained online for almost two years after the transcripts were closed for editing. All the contributions were quality checked and transferred to the digital archive of Munch's notes and letters - www.emunch.no. Projects' temporality and ephemeral nature might work as a negative affordance both for the leaders and participants, who are investing their time and effort in maintaining the platform and transcribing. Projects need longer time than is usually allowed for successful audience development.

\section{Conclusion}

Drawing on Gibson's notion of 'affordances' and actor-network theory, this paper has sought to explore whether and how the different transcription projects' interfaces empower the users and allow them to interact with the digital networked objects mediated on a computer screen. The four projects I looked at, established on two different platforms (Zooniverse and MediaWiki) dealt with transcribing similar types of archival material. However, their interfaces differed greatly already on the level of their homepages, which affordances were rather limited - they were view-able, read-able and browse-able and offered a single-clicking feature. The Zooniverse homepages focused on creating interest and enabled redirecting to the transcription box with one click, whereas the MediaWiki homepages were more informative, almost overloaded with text, and therefore more difficult to navigate and for the user to find out how to get started.

Different transcription box interfaces determined different strategies for completing transcription tasks. The most striking difference between the compared environments was how much text volunteers were expected to transcribe - a whole page (MediaWiki) or as little as one word or phrase (Zooniverse). In addition, in all the scrutinized projects the users were asked to encode structural features of the text such as underlines or erasures by using integrated toolbars. The platforms' layout and design, their features, content and embedded symbolic representations guided the users in their actions and functioned as Latourian mediators enabling production of new knowledge about the manuscripts and establishing multiple new connections between the manuscripts in the archive and outside it to the editors, the volunteers, the software and hardware (Iranowska 2018). Users' interaction with the networked objects depended highly on mediators' functionality and location. A cluttered interface with too many elements might function as a negative affordance demotivating potential users.

In order to boost the interest in the projects, MediaWiki interfaces include gamification elements, which afforded the users to compete with each other. However, in the cases at hand, collecting points and climbing the charts did not seem to bring about the desired result. Interestingly, the researchers behind the Zooniverse consciously avoided a game context and wished to afford their users the ability to contribute to a real research goal instead of introducing a game feeling.

Last, but not least, projects' length impact their ability to engage volunteers. Platforms' durability depends highly on a network of human and non-human actors that they are made of - the editors, the volunteers, software and hardware and, last but not least, the funding. An equal mobilizing of all the actors in the network takes more than one might initially think (for example, Edvard Munch's Writings ran only for a year because of unequally mobilized actors - too few volunteers and limited funding). Thinking about mobilized actors helps to secure enough means and resources to work with advertising, recruiting volunteers and sustaining their interest.

All in all, when designing a transcription crowdsourcing project, the role of the interface and its affordances should not be undervalued, since users' participation in the project is facilitated through this technology. Interfaces function as participatory objects enabling democratic production of knowledge. As the critical examination of the four projects revealed, less cluttered and more open environments, alongside dynamic and engaging interface, including exposure to historic texts already in a homepage, generate interest and may contribute to boosting participation. 
Although the analyzed projects were promoted as participatory and user-empowering, in reality they expected the volunteers to follow strict rules and solve specific tasks communicated carefully through their interfaces. Many of the platforms' affordances embodied the authoritative voice of the editors governing the projects.

Transcribing interfaces had potential to contribute to democratization of cultural institutions, but in reality the power relation between the users and editors remained traditional and unequal. Editors were still decision makers delegating the tasks. Therefore, the idea of participation and contributing to a greater good seemed to be mainly a marketing tool aimed at attracting users.

Received: 20 April 2018 Finally accepted: 8 March 2019

\section{Acknowledgements}

The author wishes to thank Brita Brenna, Hans Dam Christensen, Hilde Bøe and Victoria van Hyning for their comments on earlier versions of this essay. Thanks also to my informants, and reviewers, whose suggestions are greatly appreciated.

\section{Notes}

1 'The Transcribe Bentham project is a collaboration between University College London's Library Services (including UCL's Special Collections), the Bentham Project (based in the Faculty of Laws), UCL Centre for Digital Humanities, the British Library, and the University of London Computing Centre, with the role of the Digital Humanities centre being to provide guidance and advice with online activities, best practice, and public engagement' (Terras 2016, 11).

2 http://www.crowdsourcing.com

3 All translations my own, unless otherwise specified.

4 See https://www.zooniverse.org/about

5 See https://www.shakespearesworld.org

6 Victoria van Hyning, interview by author, digital recording via Skype, 26 June 2017, London, Oslo.

7 Victoria van Hyning, e-mail to author, 9 December 2018.

8 The research team have adjusted and developed the walkthrough method in order to study apps or other digital media which involve users' interaction with digital interface. I learned about the walkthrough method at a workshop organized by the authors at Queensland University of Technology, Australia in February 2017.

9 'One line at a time: A new approach to transcription and art history', Zooniverse 2015. https://blog.zooniverse.org/tag/annotate/, accessed 10 September 2017.

10 Victoria van Hyning, interview by author, digital recording via Skype, 26 June 2017, London, Oslo.

$11 \mathrm{XML}$ is a markup language that defines a set of rules for encoding documents in a format that can be easily converted into any number of formats.

12 A tag is a markup construct that begins with $<$ and ends with $>$.

13 Ridge, Mia, 'Reaching out: museums, crowdsourcing and participatory heritage,' Museoalan Teemapäivät 2016. https://www.youtube.com/watch?v=MbNcUqcTRdM\&t=657s, accessed 15 September 2017. 
14 Hilde Bøe, interview by author, digital recording, 27 June 2017, Oslo.

15 A volunteer, interview by author, digital recording, 30 June 2017, Oslo.

16 Valeonti, Foteini, 'The Crowdsourced Art Museum,' Crowdsourcing Week, London 2016. https://www.youtube.com/watch?v=C4s0FgON1QQ, accessed 01 August 2017.

17 Louise Seaward, interview by author, digital recording via Skype, 23 June 2017, London, Oslo.

18 Hilde Bøe, interview by author, digital recording, 27 June 2017, Oslo.

19 Valeonti, Foteini, 'The Crowdsourced Art Museum,' Crowdsourcing Week, London 2016. https://www.youtube.com/watch?v=C4s0FgON1QQ, accessed 01 August 2017, (11:15).

20 Ridge, Mia, 'Reaching out: museums, crowdsourcing and participatory heritage,' Museoalan Teemapäivät 2016. https://www.youtube.com/watch?v=MbNcUqcTRdM\&t=657s, accessed 15 September 2017, (28:01).

21 Causer, Tim 'Crowdsourcing and crowdfunding for universities and academic research in the humanities and social sciences,' MicroPasts Knowledge Exchanges 2015, UCL Institute of Archaeology. https://www.youtube.com/watch?v=|SjcUQqqTdc, accessed 15 September 2017, (4:04).

22 Victoria van Hyning, interview by author, digital recording via Skype, 26 June 2017, London, Oslo.

23 Samantha Blickhan, interview by author via Skype, digital recording, 26 June 2017, Chicago, Oslo.

24 The project was founded by the Freedom of Expression Foundation (Fritt Ord), Arts Council Norway (Norsk Kulturråd), the City of Oslo Arts Collections' Institute for Scholarly Research (Kunstsamlingenes Institutt for Vitenskapelig Forskning), Ministry of Foreign Affairs, Tate Modern and the Munch Museum).

25 Victoria van Hyning, interview by author, digital recording via Skype, 26 June 2017, London, Oslo.

26 Victoria van Hyning, interview by author, digital recording via Skype, 26 June 2017, London, Oslo.

\section{References}

Axelsson, B. (2018) 'Breaking the Frames? The Creation of Digital Curatorial Agency at Swedish Cultural History Museums', in Brenna, B., Christansen, H. D., and Hamran, O., (eds) Museums as Cultures of Copies: The Crafting of Artefacts and Authenticity, London: Routledge.

Barry, A. (2001) Political Machines: Governing a Technological Society, London \& New York: The Athlone Press.

Blaser, L. (2014) 'Old Weather: Approaching Collections from a Different Angle,' in Ridge, M. (ed) Crowdsourcing Our Cultural Heritage, 1-13, Farnham: Ashgate.

Bordalejo, B. and Robinson, P. (2016) 'Special Section on Social Digital Scholarly Editing', Digital Scholarship in the Humanities, 31, 782-910. 
Brabham, Daren C. (2013) Crowdsourcing, Cambridge \& London: The MIT Press.

Brenna, Brita (2016) 'Kvalitet og deltakelse i museer', in Prytz, E., and Prytz, O. (eds.) Kvalitetsfoståelser. Kvalitetsbegrepet i samtidens kunst og kultur, 36-52, Bergen: Fagbokforlaget.

Cameron, F. and Mengler, S. (2011) 'Activating the Networked Object for a Complex World', in Styliaras, G., Koukopoulos, D., and Lazarinis, F. (eds) Handbook of Research on Technologies and Cultural Heritage: Applications and Environments, 166-87, Hershey: Information Science Reference.

Cameron, F. and Mengler, S. (2015) 'Transvisuality, Geopolitics and Cultural Heritage in Global Flows: The Israeli- Palestinian Conflict and the Death of the Virtual...', in Kristensen, T., Michelsen, A., and Frauke. W., (eds) TransVisuality: The Cultural Dimension of Visuality, 59-72, Liverpool: Liverpool University Press.

Causer, T. and Terras, M. (2014): "'Many Hands Make Light Work. Many Hands Together Make Merry Work": Transcribe Bentham and Crowdsourcing Manuscript Collections', Ridge, M., (ed.) Crowdsourcing our Cultural Heritage, 57-88, Farnham, Surrey: Ashgate.

Causer, T. and Wallace, V. (2012) 'Building a Volunteer Community: Results and Findings from Transcribe Bentham', DHQ: Digital Humanities Quarterly, 6(2), 1-25.

Delwiche, A. and Henderson Jacobs, J. (eds) (2013) The Participatory Cultures Handbook, New York and London: Routledge.

Gibson, J. J. (1986) The Ecological Approach to Visual Perception, Hillsdale, New Jersey: Lawrence Erlbaum Associaties, Inc., Publishers.

(1978) 'The Ecological Approach to the Visual Perception of Pictures', Leonardo, 11, 227-235.

Hargittai, Eszter and Walejko, Gina (2008) 'THE PARTICIPATION DIVIDE: Content creation and sharing in the digital age', Information, Communication \& Society, 11, 239-256.

Holley, R. (2010) 'Crowdsourcing: How and Why Should Libraries Do It?', D-Lib

Magazine 16, 1-21.

Huotari, Kai and Hamari, Juho (2012) 'Defining Gamification - A Service Marketing Perspective'. MindTrek ' 12 Proceeding of the 16th International Academic MindTrek Conference, 17-22. DOI: 10.1145/2393132.2393137

Hylland, O. M. (2014) '\#Mangletre. Om makt og ideologi i den digitale kultuarvens politikk', Nordisk Kulturpolitisk Tiddskrift, 17, 253-274.

(2017) 'Even Better than the Real Thing? Digital Copies and Digital Museums in a Digital Cultural Policy', Culture Unbound, 9, 62-84.

Iranowska, J. (2019) 'Museum crowdsourcing - detecting the limits. eMunch.no and digitization of letters addressed to Edvard Munch', in Lewi, H., Smith, W., and Cooke, S. (eds) International Handbook of New Digital Practices in Galleries, Libraries, Archives, Museums and Heritage Sites, Melbourne: Routledge.

De Laet, M. and Mol, A. (2000) 'The Zimbabwe Bush Pump. Mechanics of a Fluid Technology', Social Studies of Science, 30, 225-63. 
Latour, B. (1999) Pandora's Hope: Essays on the Reality of Science Studies, London: Harvard University Press.

(2007) Reassembling the Social: An Introduction to Actor-Network-Theory, New York: Oxford University Press.

(2013) 'Biography of an Inquiry: On a Book about Modes of Existence', Social Studies of Science, 43, 287-301.

Law, J. (2009) 'Actor Network Theory and Material Semiotics', in Turner, Bryan S. (ed) The New Blackwell Companion to Social Theory, Chichester, West Sussex, United Kingdom: Wiley-Blackwell.

Light, B., Burgess, J. and Duguay, S. (2016) 'The walkthrough method: An approach to the study of apps', New media \& society, New Media and Society, 20(3), 1-20.

Marres, N. (2012) Material Participation. Technology, the Environment and Everyday Publics, London: Palgrave Macmillan.

Nielsen, J. (1994) Usability inspection methods. Conference Companion on Human Factors in Computing Systems, Boston, Massachusetts, USA: ACM.

Gosden, C., Larson, F. and Petch, A. (2007) 'Objects collect people: Past perspectives on the mind and the material world.' in Knowing Things: Exploring the collections at the Pitt Rivers Museum 1884-1945, 64-91, New York, NY: Oxford University Press.

Ridge, M. (2014) 'Crowdsourcing Our Cultural Heritage: Introduction', Ridge, Mia (ed) Crowdsourcing Our Cultural Heritage, 1-13, Farnham, Surrey: Ashgate.

Roued-Cunliffe, H. and Copeland, A. (2017a) 'Introduction: What Is Participatory Heritage?', in Roued-Cunliffe, H., and Copeland, A., (eds.): Participatory Heritage, London: Facet Publishing.

(eds.) (2017b) Participatory Heritage, London: Facet Publishing.

Silvertown, J. (2009) 'A new dawn for citizen science', Trends in Ecology \& Evolution, 24 (9) 467-71.

Simon, N. (2010) The Participatory Museum, Santa Cruz, California: Museum 2.0.

Terras, M. (2016) 'Crowdsourcing in the Digital Humanities', Schreibman, S., Siemens, R., and Unsworth, J., (eds.) A New Companion to Digital Humanities, 420-439, Malden, Oxford: Wiley-Blackwell.

Tveiten Roholdt, Sigrid (2016). Frivillighet etter museumsreformen: Profesjonalisering og deltakelse, Oslo: University of Oslo.

*Joanna Iranowska is a PhD-candidate in Museum Studies at the University of Oslo. Between 2012 and 2015 she worked as a research assistant on the project Edvard Munch's Writings. She is a part of the research project Museum: A Culture of Copies and is currently working on her dissertation on digital reproductions within the art museum context with a specific focus on the collection of the Munch Museum in Oslo, Norway.

Doctoral Research Fellow - Department of Culture Studies and Oriental Languages

Centre for Museum Studies, University of Oslo

Postboks 1010 Blindern 0315 Oslo, Norway

$+4746369520$

$+47-22855235$ 